\title{
Can't escape it: the out-of-pocket cost of health care in Australia
}

Farhat Yusuf Honorary Professor of Public Health an ography, and Emeritus Professor ${ }^{2}$

Stephen R Leeder MD, PhD, FRACP Professor of Public Health and Community Medicine

1 Menzies Centre for Healt Policy, Sydney School of Public Health

University of Sydney,

Sydney, NSW.

2 Department of Marketing and Management, Faculty of Business and Economics,

Macquarie University, Sydney, NSW.

farhat.yusuf@ sydney.edu.au

MJA 2013; 199: 475-478 doi: 10.5694/mjal2.11638

Editorial p 442 niversal health insurance and social welfare systems seek to lower the barrier to health care due to cost to the patient at the time of need. However, because health care costs, especially in economically advanced nations, tend to increase rapidly, many countries with universal health insurance have backed away from complete coverage and have returned to the individual partial responsibility to contribute to the cost of health care at the time that a person seeks care. Consequently payments made from private pockets have been rising steadily.

Australia spent over $\$ 121$ billion on health care during the financial year 2009-10. Estimates from the Australian Institute of Health and Welfare (AIHW) show that $44 \%$ came from the federal government, $26 \%$ from state and local governments and $18 \%$ from copayments and direct cash outlays made by individuals. ${ }^{1}$

Many studies of health care expenditure in Australia have analysed aggregated data. ${ }^{2-4}$ Others were based on localised and/or qualitative information pertaining to, for example, the cost of chronic illness and disability, ${ }^{5}$ stroke $^{6}$ and obstructive pulmonary disease. ${ }^{7}$ A health expenditure study based on a survey of Australian households conducted in 2003-2004 was published in 2008. ${ }^{8}$

In this study, we used information from a recent national survey of Australian households to estimate their annual out-of-pocket (OOP) expenditure on health care. The OOP expenditure was defined as payments not covered by Medicare, private health insurance (PHI) or any other similar sources. It included PHI premiums, any payments to doctors, dentists and other health practitioners (excluding Medicare or PHI rebates), copayments for medicines covered by the Pharmaceutical Benefits Scheme

Objective: To analyse the annual out-of-pocket (OOP) expenditure on health care as directly reported by Australian households grouped into older households (those with a reference person aged $\geqslant 65$ years) and younger households (those with a reference person aged $<65$ years).

Design: Descriptive analysis of statutory data collected by the Australian Bureau of Statistics.

Setting and participants: Probability sample of 9774 households across all states and territories.

Main outcome measures: OOP expenditure on health care.

Results: The mean annual OOP expenditure on health care among the older households was estimated as $\$ 3585 \pm \$ 686$ (9.4\% of the total expenditure on all goods and services), and among the younger households, it was $\$ 3377 \pm \$ 83$ ( $4.7 \%$ of the total expenditure on all goods and services). Cost of medicines (mainly non-prescription drugs and to a lesser extent the copayments for Pharmaceutical Benefits Scheme scripts) was the biggest item of expenditure for the older households, and the cost of private health insurance $(\mathrm{PHI})$ was the most expensive item for the younger households. Overall, the OOP expenditure, as reported by the Australian households, was $\$ 28.7 \pm \$ 1.3$ billion compared with $\$ 21.2$ billion as reported by the Australian Institute of Health and Welfare. Unlike our estimate, the Institute's figure was based on statutory data collections and did not include the cost of PHI premiums.

Conclusions: OOP expenses account for almost a quarter (22\%) of the total health care costs in Australia. The mean annual OOP expenditure was slightly higher for the older households compared with the younger households, despite the fact that the older households had significantly lower income and had greater access to health care cards, which were used to defray additional health care costs associated with age.

(PBS), non-prescription medicines, other pharmaceutical and therapeutic goods, and hospital and other health care costs not covered by Medicare or PHI.

\section{Methods}

The Household Expenditure Survey (HES) was conducted by the Australian Bureau of Statistics (ABS) over 1 year beginning July 2009. Details of the survey methods and a full list of the expenditure items are available on the ABS website. ${ }^{9}$

Briefly, private dwellings were selected using a stratified, multistage, cluster sampling procedure. According to the ABS, the sample was representative of most (97\%) of the population of Australia. Those excluded mainly consisted of people living in very remote areas, residents of non-private dwellings, and foreign diplomats and armed forces stationed in Australia.

Experienced ABS interviewers were given comprehensive training and detailed written instructions to complement the survey documents so as to minimise response errors. Within each household, a person was selected as the "reference person". This person was selected using criteria such as being a partner in a registered marriage or de-facto relationship, a lone parent with one or more dependent children, the person with highest income, or the eldest person in the household. Data on household characteristics, housing costs, assets and liabilities, and items of expenditure common to all household members were obtained from the reference person. Diaries were provided to all members of the household aged 15 years or 


\begin{tabular}{|c|c|c|c|c|}
\hline \multirow[b]{2}{*}{ Household characteristics } & \multicolumn{2}{|c|}{$\begin{array}{l}\text { Older households } \\
\text { (reference person* aged } \geqslant 65 \text { years) }\end{array}$} & \multicolumn{2}{|c|}{$\begin{array}{l}\text { Younger households } \\
\text { (reference person* aged }<65 \text { years) }\end{array}$} \\
\hline & $\begin{array}{l}\text { Mean annual } \\
\text { OOP expenditure }\end{array}$ & SEM & $\begin{array}{l}\text { Mean annual } \\
\text { OOP expenditure }\end{array}$ & SEM \\
\hline \multicolumn{5}{|l|}{ Household composition } \\
\hline Couples only & $\$ 3432$ & $\$ 122$ & $\$ 3724$ & $\$ 139$ \\
\hline Couples with children ${ }^{\dagger}$ & $\$ 5098$ & $\$ 966$ & $\$ 4453$ & $\$ 118$ \\
\hline Single parents with children ${ }^{\dagger}$ & $\$ 1927$ & $\$ 164$ & $\$ 2184^{\ddagger}$ & $\$ 629$ \\
\hline Lone persons & $\$ 1953$ & $\$ 242$ & $\$ 1737$ & $\$ 146$ \\
\hline Others & $\$ 11331^{5}$ & $\$ 8271$ & $\$ 2729$ & $\$ 181$ \\
\hline \multicolumn{5}{|l|}{ Income quintile } \\
\hline Quintile 1 (lowest 20\%) & $\$ 2066$ & $\$ 197$ & $\$ 1862$ & $\$ 377$ \\
\hline Quintile 2 & $\$ 2748$ & $\$ 107$ & $\$ 1884$ & $\$ 177$ \\
\hline Quintile 3 & $\$ 9349^{\$}$ & $\$ 5953$ & $\$ 2678$ & $\$ 138$ \\
\hline Quintile 4 & $\$ 5086$ & $\$ 758$ & $\$ 3672$ & $\$ 156$ \\
\hline Quintile 5 (top 20\%) & $\$ 8226$ & $\$ 1182$ & $\$ 5619$ & $\$ 177$ \\
\hline \multicolumn{5}{|l|}{ One or more health care cards } \\
\hline No & $\$ 5445$ & $\$ 747$ & $\$ 3795$ & $\$ 84$ \\
\hline Yes & $\$ 3357$ & $\$ 781$ & $\$ 2357$ & $\$ 186$ \\
\hline \multicolumn{5}{|l|}{ Private health insurance } \\
\hline No & $\$ 1481$ & $\$ 184$ & $\$ 1284$ & $\$ 64$ \\
\hline Yes & $\$ 5655$ & $\$ 1345$ & $\$ 5087$ & $\$ 137$ \\
\hline
\end{tabular}

SEM = standard error of mean. * One person in each household was selected as the "reference person". This person was selected using criteria such as being a partner in a registered marriage or de-facto relationship, a lone parent with one or more dependent children, the person with highest income, or the eldest person in the household. IIncluding both dependent and non-dependent children. $\neq$ Estimate subject to relative standard error (RSE) of $25 \%$ to $<50 \%$ and should be treated with caution. $\oint$ Estimate subject to RSE of $\geqslant 50 \%$ and is very unreliable.

older to record information on their expenses over two 1-week periods.

We obtained de-identified records for each of the 9774 households in the sample through an arrangement between the ABS and the University of Sydney. These records included the characteristics of households and the mean weekly expenditure on various goods and services purchased by the household members. These estimates of weekly household expenditure did not refer to any particular week. They were derived by the ABS for each expenditure item by dividing the reported expenditure for all members of the household on that item by the number of weeks in the relevant recall period. In the context of health care expenditure, the recall periods were 12 months for the cost of PHI, 3 months for health practitioners' fees and hospital and nursing home charges, and 2 weeks for PBS prescription and non-prescription drugs and other pharmaceutical products.

The ABS provided data on mean weekly expenditures, and these were converted into annual figures by using the multiplier $365.25 / 7$. The national estimates of the OOP expenditure for various health-related items were determined by multiplying the mean household expenditure on a specific item by the estimated number of households in Australia.

Results are expressed as mean \pm standard error of mean (SEM). SEM was calculated following the procedure outlined by the ABS, ${ }^{9}$ and the $5 \%$ level of significance was used to test the significance of differences in OOP expenditures. Relative standard error (RSE) for a mean $x$ was defined as: $\operatorname{RSE}(x)=\operatorname{SEM}(x) / x$. It is usually expressed as a percentage of $x$.

\section{Results}

\section{Profile of households}

Our estimates show that there were $8.40 \pm 0.03$ million households in Australia; of these $1.76 \pm 0.02$ million had a reference person aged $\geqslant 65$ years, and are referred to as the older households. Thus, older households accounted for just over one in five households. The two groups of households, older and younger, varied significantly in terms of their living arrangements (household composition), income, access to health care cards and PHI.
Most of the older households $(86 \% \pm 1.2 \%)$ consisted of couples only or lone persons, while most of the younger households $(63 \% \pm 0.5 \%)$ were couples with or without children. Consequently, the mean household size was $1.72 \pm 0.02$ people for the older households and $2.78 \pm 0.01$ people for the younger households.

About half of the older households were in the lowest income quintile (lowest 20\%), and slightly more than one in 10 of the younger households were also in this low-income group. While $89 \% \pm 0.8 \%$ of the older households had one or more health care cards, the figure for younger households was $29 \% \pm 0.6 \%$. Despite their lower income levels, $50 \% \pm 1.3 \%$ of the older households had PHI; this was only marginally lower than in the younger households $(55 \% \pm 0.8 \%)$.

\section{Out-of-pocket expenditure by households}

The mean household expenditure on health care in the older households was $\$ 3585 \pm \$ 686$ per annum, while in the younger households it was $\$ 3377 \pm \$ 83$. The OOP expenditure of the two types of households was not statistically significantly different. 
2 Mean annual out-of-pocket (OOP) expenditure on health care by item of expenditure, from Household Expenditure Survey 2009-20109

\begin{tabular}{|c|c|c|c|c|c|}
\hline \multirow[b]{2}{*}{ Item of expenditure } & \multirow[b]{2}{*}{$\begin{array}{l}\text { Reference } \\
\text { period }^{\dagger}\end{array}$} & \multicolumn{2}{|c|}{$\begin{array}{l}\text { Older households } \\
\text { (reference person* } \\
\text { aged } \geqslant 65 \text { years) }\end{array}$} & \multicolumn{2}{|c|}{$\begin{array}{l}\text { Younger households } \\
\text { (reference person }^{*} \\
\text { aged }<65 \text { years) }\end{array}$} \\
\hline & & $\begin{array}{l}\text { Mean annual } \\
\text { OOP expenditure }\end{array}$ & SEM & $\begin{array}{l}\text { Mean annual } \\
\text { OOP expenditure }\end{array}$ & SEM \\
\hline Private health insurance & 12 months & $\$ 1056$ & $\$ 42$ & $\$ 1471$ & $\$ 33$ \\
\hline Hospital, medical and dental insurance & 12 months & $\$ 1009$ & $\$ 31$ & $\$ 1196$ & $\$ 25$ \\
\hline Ambulance, sickness and personal insurance & 12 months & $\$ 47^{\ddagger}$ & $\$ 30$ & $\$ 275$ & $\$ 19$ \\
\hline Health practitioners' fees & 3 months & $\$ 753$ & $\$ 56$ & $\$ 1054$ & $\$ 65$ \\
\hline GPs' fees & 3 months & $\$ 43$ & $\$ 5$ & $\$ 98$ & $\$ 4$ \\
\hline Specialists' fees & 3 months & $\$ 289$ & $\$ 29$ & $\$ 335$ & $\$ 52$ \\
\hline Dental fees & 3 months & $\$ 258$ & $\$ 41$ & $\$ 409$ & $\$ 28$ \\
\hline Opticians' fees (including spectacles) & 3 months & $\$ 87$ & $\$ 10$ & $\$ 78$ & $\$ 7$ \\
\hline Physiotherapists' and chiropractors' fees & 3 months & $\$ 26$ & $\$ 5$ & $\$ 79$ & $\$ 6$ \\
\hline Other health practitioners' fees & 3 months & $\$ 50^{\S}$ & $\$ 19$ & $\$ 55$ & $\$ 7$ \\
\hline Medicines, pharmaceuticals and therapeutic products & $2 \times 1$ week & $\$ 1563^{\S}$ & $\$ 693$ & $\$ 764$ & $\$ 25$ \\
\hline Prescriptions & $2 \times 1$ week & $\$ 383$ & $\$ 35$ & $\$ 282$ & $\$ 15$ \\
\hline Other medicines and pharmaceutical products & $2 \times 1$ week & $\$ 797^{\S}$ & $\$ 344$ & $\$ 443$ & $\$ 15$ \\
\hline First aid supplies and other therapeutic products & $2 \times 1$ week & $\$ 383^{\ddagger}$ & $\$ 350$ & $\$ 39$ & $\$ 6$ \\
\hline Other health care and medical expenses & Mixed (as shown below) & $\$ 213^{\S}$ & $\$ 80$ & $\$ 88$ & $\$ 13$ \\
\hline Hospital and nursing home charges & 12 months & $\$ 183^{\delta}$ & $\$ 80$ & $\$ 73$ & $\$ 12$ \\
\hline $\begin{array}{l}\text { Other health care and medical expenses not } \\
\text { elsewhere classified }\end{array}$ & $2 \times 1$ week & $\$ 30^{\S}$ & $\$ 13$ & $\$ 15^{\S}$ & $\$ 4$ \\
\hline Total OOP expenditure on health care & Mixed (as shown above) & $\$ 3585$ & $\$ 686$ & $\$ 3377$ & $\$ 83$ \\
\hline Total expenditure on all goods and services & $\begin{array}{l}\text { Various reference periods } \\
\text { depending on the item }\end{array}$ & $\$ 37922^{q}$ & $\$ 1315$ & $\$ 71511^{9}$ & $\$ 630$ \\
\hline
\end{tabular}

SEM = standard error of mean. * One person in each household was selected as the "reference person". This person was selected using criteria such as being a partner in a registered marriage or de-facto relationship, a lone parent with one or more dependent children, the person with highest income, or the eldest person in the household. † Reference period refers to 12-month and 3-month recall periods before the interview, or two 1-week periods recorded in a diary after the interview. $\ddagger$ Estimate subject to relative standard error (RSE) of $\geqslant 50 \%$ and is very unreliable. $\$$ Estimate subject to RSE of $25 \%$ to < $50 \%$ and should be treated with caution. 9 Three households reporting a negative total expenditure on all goods and services were excluded from the analysis.

However, the mean annual household expenditure on all goods and services was $\$ 37922 \pm \$ 1315$ for the older households, compared with $\$ 71511 \pm \$ 630$ for the younger households. Thus, even though the OOP expenditure on health care was similar for both types of households, when expressed as a proportion of their total household budget, the OOP expenditure incurred by the older households $(9.4 \% \pm 0.3 \%)$ was much higher than that of the younger households $(4.7 \% \pm 0.1 \%)$. Because of the substantial difference in the mean size of the two types of households, the mean per-capita OOP expenditure on health care was estimated to be $\$ 1991 \pm \$ 240$ for the older and $\$ 1389 \pm \$ 43$ for the younger households.

A comparison of the OOP expenditure on health care by household composition shows that the older households incurred higher OOP expenditure than the younger households, with the exception of the category of single parents with children.
This category accounted for a miniscule proportion of the older households and around $8 \%$ of the younger households, and therefore a meaningful comparison is not possible (Box 1).

Overall, for both the older and younger households, the OOP expenditure on health care seemed to be positively associated with income. Moreover, households with one or more health care cards spent much less than those without these concession cards. Both younger and older households that had PHI cover spent about four times more than those that did not have such cover (Box 1). About half of this difference represented the cost of PHI premiums.

\section{Itemised out-of-pocket expenditure on health}

Box 2 shows that the cost of medicines (mainly non-prescription drugs and to a lesser extent the copayments for PBS scripts) was the biggest item of OOP expenditure for the older households, while the PHI premiums were the biggest expense for the younger households. Younger households spent substantially more on health practitioners' fees but much less on both prescription and nonprescription medicines compared with older households.

\section{Contribution of the out-of-pocket expenditure to the total health budget in Australia}

Nationally, the OOP expenditure on health care by the older households was estimated to be $\$ 6.3 \pm \$ 1.2$ billion annually compared with $\$ 22.4 \pm \$ 0.6$ billion by the younger households. Thus the total national OOP expenditure on health care as reported by Australian households was $\$ 28.7 \pm \$ 1.3$ billion in the 2009-10 financial year.

\section{Discussion}

This study of Australian households shows that the mean annual OOP expenditure on health care was 
$\$ 3585 \pm \$ 686$ for the older and $\$ 3377 \pm \$ 83$ for the younger households. Non-prescription drugs were the biggest item of expenditure for the older households, and PHI premiums were the biggest item for the younger households. These and other differences presented in this study could partly be due to the larger proportion of older households having access to health care and other concession cards with substantially lower safetynet thresholds. Although the prevalence of ill health is generally higher among the older households, their OOP expenditure on health practitioners' fees was substantially lower than that of the younger households. This may be the result of concessions from health practitioners and/or older individuals not using what may be appropriate health services.

While universal health insurance mitigates the costs of health care for sick individuals, OOP expenses can be substantial in both absolute and relative terms. Such costs can be extremely heavy and indeed crippling. The long-drawn-out expenses incurred by individuals with multiple chronic diseases are one example. ${ }^{5} \mathrm{~A}$ more selective approach to the provision of public support for health care, with those who need the most receiving the most, might partially remedy the OOP expenditure problem. Safety nets could be developed based on careful elucidation of the needs of individuals by consultation. The decline in the adequacy of coverage of Medicare rebates for medical services has increased the need for copayments and deserves review.
We cannot tell from the data used in this paper the extent to which OOP expenses limit access to health care or what other goods and services are forgone to meet these expenses. However, from other studies we know that when OOP costs are anything more than trivial, individuals with low incomes and multiple health problems will suffer the most. ${ }^{5-7}$ That older people spend relatively more OOP for health care may be because they see greater benefit in it than do younger people.

The strength of this study lies in the direct report of a representative sample of members of the community about their personal health expenditure. It is a focused snapshot of what Australians believe they are paying from their own pocket for health care. The study, however, does not extend to the assessment of financial records and is based on estimates provided by the participants. While our estimate of OOP expenditure is substantially higher than the AIHW estimate of $\$ 21.2$ billion for the same year, ${ }^{1}$ the Institute's figure was based on statutory data collections and did not include the cost of PHI premiums.

It is reassuring that the national estimate of total OOP expenditure presented in this paper does not differ greatly from the AIHW estimate based on macrofinancial transactions, if the cost of PHI premiums is included.

Policy discourse about paying for health care should recognise the size and the social and personal significance of the OOP contribution in determining policy. Detailed exami- nation of the effect of OOP costs on service use according to socioeconomic level of the user would be helpful in arranging compensatory finance for those least able to afford it. At present it is a case of "out-of-pocket: out-of-policy".

Competing interests: Stephen Leeder is currently Editorin-Chief of the Medical Journal of Australia. The approval process for publication of this manuscript was completed before his appointment to this position.

Received 7 Nov 2012, accepted 8 Jul 2013.

1 Australian Institute of Health and Welfare. Health expenditure, Australia 2009-10. Canberra: AlHW, 2011. (AlHW Cat. No. HWE 55.) http://www.aihw.gov.au/WorkArea/ DownloadAsset.aspx?id=10737420254 (accessed Sep 2013).

2 Ang JB. The determinants of health care expenditure in Australia. Appl Econ Lett 2010; 17:639-644.

3 Schofield D. Public hospital expenditure: how is it divided between lower, middle and upper income groups? Aust Econ Rev 2000; 33: 303-316.

4 Barrett GF, Conlon R. Health care spending: family structure and family health. Econ Lab Rel Rev 2003; 14: 143-152.

5 Jan S, Essue BM, Leeder SR. Falling through the cracks: the hidden economic burden of chronic illness and disability on Australian households. Med J Aust 2012; 196: 29-31.

6 Dewey HM, Thrift AG, Mihalopoulos C, et al. 'Out of pocket' costs to stroke patients during the first year after stroke - results from the North East Stroke Incidence Study. J Clin Neurosci 2004; 11: 134-137.

7 Essue B, Kelly P, Roberts M, et al. We can't afford my chronic illness! The out-of-pocket burden associated with managing chronic obstructive pulmonary disease in western Sydney, Australia. $J$ Health Serv Res Policy 2011; 16: 226-231.

8 Jones G, Savage E, van Gool K. The distribution of household health expenditures in Australia. Econ Rec 2008; 84: S99-S114.

9 Australian Bureau of Statistics. Household Expenditure Survey and Survey of Income and Housing, User Guide, 2009-10. Canberra: ABS, 2012. (ABS Cat. No. 6503.0.) http://www.abs. gov.au/AUSSTATS/abs@.nsf/DetailsPage/ 6503.02009-10?OpenDocument (accessed Sep 2013).
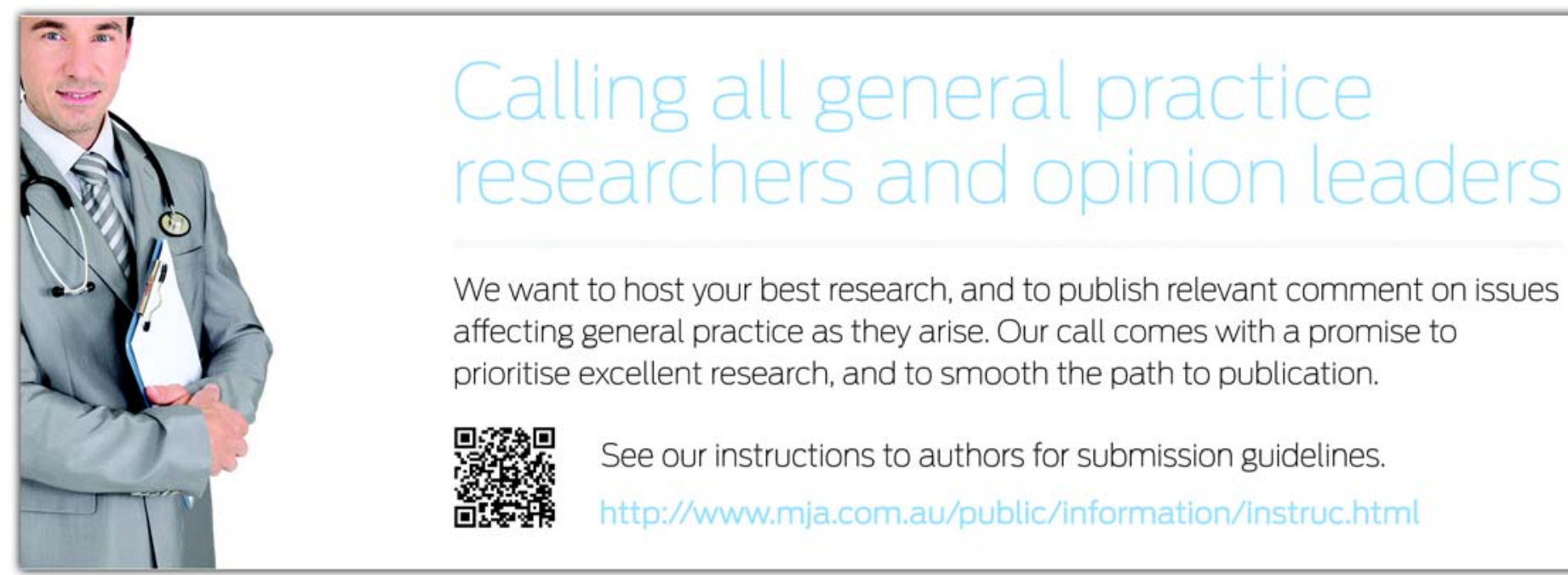

We want to host your best research, and to publish relevant comment on issues affecting general practice as they arise. Our call comes with a promise to prioritise excellent research, and to smooth the path to publication.

See our instructions to authors for submission guidelines. 